Journal homepage: http://www.journalijar.com

Journal DOI: $\underline{\text { 10.21474/IJAR01 }}$

RESEARCH ARTICLE
INTERNATIONAL JOURNAL

OF ADVANCED RESEARCH

מחים"

ISSN NO. 2320-5407

\title{
COMPARATIVE STUDY OF EQUATION OF STATE FOR SOME IONIC CRYSTALS.
}

Mahendra Mehra*, Seema Rajput.

Department of Physics, Govt. Motilal Vigyan Mahavidyalaya, Bhopal (M. P.), India 462008

\section{Manuscript Info}

Manuscript History:

Received: 17 March 2016

Final Accepted: 02 May 2016

Published Online: May 2016

Key words:

Equation of State (EOS), Isothermal Bulk Modulus, Pressure derivatives

of Isothermal Bulk Modulus.

*Corresponding Author

Mahendra Mehra.

\begin{abstract}
The phenomenological forms for isothermal equations of state (EOS) of solids have played a very important role in the field of high-pressure physics. An isothermal EOS is used to study the relationship between pressure $\mathrm{P}$ and volume compression at a given temperature. It is also used to study the isothermal bulk modulus $\mathbf{B}_{\mathrm{T}}$ and its pressure derivatives $\mathrm{B}_{\mathrm{T}}$ and $\mathrm{B}^{\prime \prime} \mathrm{T}$, respectively. In the present study we have taken five different forms of EOS which contain $\mathrm{B}_{0}$ and $\mathrm{B}_{0}{ }_{0}$ only. Using these forms we have studied the pressure-volume relationships for $\mathrm{MgO}$ at room temperature and at different range of temperatures. The results for pressure $\mathrm{P}$, isothermal bulk modulus $\mathrm{B}_{\mathrm{T}}$ and pressure derivative $\mathrm{B}_{\mathrm{T}}$ obtained from different equations are compared. The comparison reveals that the all EOS yield very similar results.
\end{abstract}

Copy Right, IJAR, 2016,. All rights reserved.

\section{Introduction:-}

Strength and elastic properties of a solid depend on the strength of its interatomic forces. Therefore, the application of pressure which changes interatomic distance of the substances changes its physical properties. This pressure versus volume relation is known as Equation of State and may be quite useful to understand the physical properties of the material. The earth's mantle is primarily composed of silicate and Oxides(e.g. $\mathrm{Mg}, \mathrm{Fe}) \mathrm{O}$ ).

$\mathrm{MgO}$ has low chemical reactivity and it is stable in a large pressure and temperature range. A simple theoretical model is developed to study the high pressure behavior of solids and is applied to evaluate the pressure for $\mathrm{MgO}$ in case of large compression along with Shanker, Tait, Vinet, and Birch-Murnaghan equation of states (EOSs). It is found that for the high pressure compression behavior of $\mathrm{MgO}$ the present model, Tait, Vinet, and Birch-Murnaghan EOSs give the results compatible with the experimental data. It has also been found that in the regime of ultrahigh pressure the present model and Birch-Murnaghan EOS satisfy the Stacey criterion.

Values of $\mathbf{B}_{\mathbf{0}}$ and $\mathbf{B}_{\mathbf{0}}$ estimated corresponding to different temperatures are used appropriately as input data. Isaak et al. [1] have determined the thermoelastic properties of $\mathrm{MgO}$ at high temperatures and high pressures using the potential induced breathing (PIB) electron gas model based on the first principles approach. The ab-initio method of Isaak et al. is based on the detailed calculations of the Helmholtz energy $\mathrm{F}$ versus volume at constant temperature $\mathrm{T}$ at selected temperatures. By taking the appropriate derivatives of $F$, values of pressure $P$, isothermal bulk modulus $\mathrm{B}_{\mathrm{T}}$ and its pressure derivative $\mathrm{B}_{\mathrm{T}}$ are numerically determined. The results thus obtained have been found to present good agreement with the measurements of the temperature dependence of thermoelastic properties [2,3]. The values of $\mathrm{P}, \mathrm{B}_{\mathrm{T}}$ and $\mathrm{B}_{\mathrm{T}}$ for $\mathrm{MgO}$ at , 1000 and $2000 \mathrm{~K}$ and down to a compression of $\mathrm{V} / \mathrm{V} 0=0.60$ determined by Isaak et al. have been reported in the tabular form by Anderson [4].

The various phenomenological forms for the isothermal equation of state are given below for ready reference $\mathbf{P}=\frac{\mathbf{B}_{0}}{\left(\mathrm{~B}_{\mathbf{0}}{ }^{\prime}+1\right)}\left[\left\{\exp \left(\mathrm{B}_{0}{ }^{`}+1\right)\left(1-\frac{\mathrm{V}}{\mathrm{V0}}\right)\right\}-1\right]$ 
$\left.B_{T}=B_{0}\left(\frac{V}{V_{0}}\right) \exp \left[B_{0}{ }^{\prime}+1\right)\left(1-\frac{V}{V_{0}}\right)\right]$

$\mathbf{B}_{\mathrm{T}}^{\prime}=\left(\mathbf{B}_{\mathbf{0}}{ }^{\prime}+\mathbf{1}\right) \frac{\mathbf{V}}{\mathbf{V}_{\mathbf{0}}}-\mathbf{1}$

The above equation is the usual Tait equation (UTE) frequently reported in the literature [6,7,9,11]. The UTE has been reproduced recently by Kumar [12] using the Chopelas-Boehler relationship [13] according to which $\left(\delta_{\mathrm{T}}+1\right)$ varies as $\mathrm{V} / \mathrm{V}_{0}$, and taking the Anderson Gruneisen parameter $\delta_{\mathrm{T}}=\mathrm{dKT} / \mathrm{dP}[14]$.

$\mathbf{P}=3 \frac{\mathbf{B}_{0}}{\left(3 \mathbf{B}_{0}-8\right)}\left[\left(\frac{V}{V_{0}}\right)^{\frac{4}{3}-B_{0}}-\left(\frac{V}{V_{0}}\right)^{\frac{-4}{3}}\right]$

$B_{T}=B_{0}\left(\frac{V}{V_{0}}\right)^{\frac{4}{3}-B_{0}}+\frac{4}{3} P$

$B_{T}^{`}=\left(1-\frac{4}{3} \frac{P}{B_{T}}\right) B_{0} `+\frac{16}{9} \frac{P}{B_{T}}$

The above equation is the well known Born Mie equation based on an inverse power form for the short-range repulsive potential energy $[4,15]$.

$\mathbf{P}=\left[\frac{3 \mathrm{~B}_{0}\left(\frac{\mathrm{V}}{\mathrm{V}_{0}}\right)^{\frac{-4}{3}}}{\left(3 \mathrm{~B}_{0}{ }^{\circ}-5\right)}\right]\left[\exp \left\{\left(\frac{3 \mathrm{~B}_{0}{ }^{\circ}-5}{3}\right)\left(1-\frac{\mathrm{V}}{\mathrm{V}_{0}}\right)\right\}-1\right]$

$B_{T}=B_{0}\left(\frac{V}{V_{0}}\right)^{\frac{-1}{3}} \exp \left\{\left(B_{0} \backslash-\frac{5}{3}\right)\left(1-\frac{V}{V_{0}}\right)\right\}+\frac{4}{3} P$

$B_{T}{ }^{\prime}=\left(1-\frac{4}{3} \frac{P}{B_{T}}\right)\left[\left(B_{0} `-\frac{5}{3}\right) \frac{V}{V_{0}}+\frac{5}{3}\right]+\frac{16}{9} \frac{P}{B_{T}}$

The above equation is the Brennan Stacey equation $[6,16]$ derived using the free volume formula for the Gruneisen parameter and taking the second Gruneisen constant $\mathrm{q}=1$.

$P=\frac{B_{0}\left(\frac{V}{V_{0}}\right)^{\frac{-4}{3}}}{t}\left[1-\frac{1}{t}+\frac{2}{t^{2}}\right)\left\{\exp (t y-1\}+y\left(1+y-\frac{2}{t}\right) \exp (t y)\right]$

$B_{T}=B_{0}\left(\frac{V}{V_{0}}\right)^{\frac{-1}{3}}\left(1+y+y^{2}\right) \exp (t y)+\frac{4}{3} p$

$B_{T}{ }^{\prime}=\frac{4}{3}+\left(1-4 / 3 \frac{P}{B_{T}}\right)\left[\frac{1}{3}+\frac{V}{V_{0}}\left\{t+\frac{(1+2 y)}{\left(1+y+y^{2}\right)}\right\}\right]$

Where $\mathrm{t}=\mathrm{B}_{0}{ }^{`}-\left(\frac{8}{3}\right)$

The above equation is the Shanker equation derived using a combined form of inverse power dependence and an exponential dependence for the short-range force constant on volume [17].

$\mathbf{P}=3 \frac{(1-X) \mathbf{B}_{0}}{\mathbf{X}^{2}} \exp \{\mathbf{n}(1-X)\}$

The above equation is the Vinet equation of state [18,19] based on an expression for the cohesive energy of a condensed system that is assumed to vary only as a function of a normalized inter particle separation $\mathrm{r}$. The interatomic interaction in solids related mainly to compression was expressed by a form A(1+ar) exp(-br) with A, a and $\mathrm{b}$ as material constants. This form leads to the derivation of the Vinet equation of state.

$P=\frac{3}{2} B_{0}\left(x^{-7}-x^{-5}\right)\left[1+\frac{3}{4} A_{1}\left(x^{-2}-1\right)\right]$

$B_{T}=\frac{1}{2} B_{0}\left(7 x^{-7}-5 x^{-5}\right)+\frac{3}{8} B_{0} A_{1}\left(9 x^{-9}-14 x^{-7}+5 x^{-5}\right)$

$B_{T}{ }^{\prime}=\frac{B_{0}}{8 B_{T}}\left[\left(B_{0}^{`}-4\right)\left(81 x^{-9}-98 x^{-7}+25 x^{-5}\right)+\frac{4}{3}\left(49 x^{-7}-25 x^{-5}\right)\right]$

The above equation is the Birch Murnaghan third-order EOS widely used in geophysics and high-pressure physics [4-6]. 


\section{Result and Discussion:-}

For studying the pressure volume relationships at high temperatures we need the input parameters $\mathrm{B}_{0}$ and $\mathrm{B}_{0}{ }_{0}$ corresponding to these temperatures. We use the ab-initio values at $\mathrm{P}$ "0 obtained by Isaak et al. [1] for $\mathrm{MgO}$ at, 1000 and $2000 \mathrm{~K}$ as reported by Anderson [4]. These are given in Table 1 and used as input for all the equations of state under study without making any adjustment or fitting.

Table 1:- Values of input data for $\mathrm{MgO}$

\begin{tabular}{|c|c|c|}
\hline Temperature $(\mathbf{K})$ & $\mathbf{B}_{\mathbf{0}}(\mathbf{G P a})$ & $\mathbf{B}_{\mathbf{0}}^{\prime}$ \\
\hline 1000 & 160 & 4.36 \\
\hline 2000 & 128 & 4.74 \\
\hline
\end{tabular}

The results for pressure $\mathrm{P}$, isothermal bulk modulus $\mathrm{B}_{T}$ and pressure derivative $\mathrm{B}_{\mathrm{T}}{ }_{\mathrm{T}}$ obtained from different equations are being compared for the efficiency of all the above EOS taken under consideration. The comparison thus proves that all the equation of state taken in the study gives very similar results

The values of pressure $\mathrm{P}(\mathrm{GPa})$ for $\mathrm{MgO}$ at different temperatures have been calculated using Usual Tait Equation of State(A), Born Mie Equation of State (B), Shankar Equation of State (C), Vinet Equation of State (D) and BirchMurnaghan Equation of State (E) in the tables $2 \& 3$ given below.

Table 2: Values of Pressure $\mathrm{P}(\mathrm{GPa})$ for $\mathrm{MgO}$ at different compressions at $\mathrm{T}=1000 \mathrm{~K}$

\begin{tabular}{|c|c|c|c|c|c|}
\hline V/Vo & $\mathbf{A}(\mathbf{P})$ & $\mathbf{B}(\mathbf{P})$ & $\mathbf{C}(\mathbf{P})$ & $\mathbf{D}(\mathbf{P})$ & $\mathbf{E}(\mathbf{P})$ \\
\hline 1 & 0 & 0 & 0 & 0 & 0 \\
\hline 0.9 & 21.2 & 21.2 & 21.2 & 21.1 & 21.2 \\
\hline 0.8 & 57.4 & 58.4 & 57.4 & 57.3 & 58.3 \\
\hline 0.7 & 119 & 126 & 120 & 120 & 125 \\
\hline 0.6 & 225 & 257 & 232 & 233 & 253 \\
\hline
\end{tabular}

Table 3: Values of Pressure $\mathrm{P}(\mathrm{GPa})$ for $\mathrm{MgO}$ at different compressions at $\mathrm{T}=2000 \mathrm{~K}$

\begin{tabular}{|c|c|c|c|c|c|}
\hline $\mathbf{V} / \mathbf{V o}$ & $\mathbf{A}(\mathbf{P})$ & $\mathbf{B}(\mathbf{P})$ & $\mathbf{C}(\mathbf{P})$ & $\mathbf{D}(\mathbf{P})$ & $\mathbf{E}(\mathbf{P})$ \\
\hline 1 & 0 & 0 & 0 & 0 & 0 \\
\hline 0.9 & 17.3 & 17.3 & 17.3 & 17.3 & 17.3 \\
\hline 0.8 & 48 & 48.9 & 47.9 & 47.8 & 48.6 \\
\hline 0.7 & 103 & 109 & 103 & 102 & 107 \\
\hline 0.6 & 199 & 230 & 204 & 203 & 224 \\
\hline
\end{tabular}

The values of isothermal bulk modulus $\mathrm{B}_{\mathrm{T}}(\mathrm{GPa})$ for $\mathrm{MgO}$ at different temperatures have been calculated using Usual Tait Equation of State(A), Born Mie Equation of State (B), Shankar Equation of State (C), Vinet Equation of State (D) and Birch-Murnaghan Equation of State (E) in the tables $4 \& 5$ given below.

Table 4: Values of isothermal bulk modulus $\mathrm{B}_{\mathrm{T}}(\mathrm{GPa})$ for $\mathrm{MgO}$ at $\mathrm{T}=1000 \mathrm{~K}$.

\begin{tabular}{|c|c|c|c|c|c|}
\hline $\mathbf{V} / \mathbf{V o}$ & $\mathbf{A}\left(\mathbf{B}_{\mathbf{T}}\right)$ & $\mathbf{B}\left(\mathbf{B}_{\mathbf{T}}\right)$ & $\mathbf{C}\left(\mathbf{B}_{\mathbf{T}}\right)$ & $\mathbf{D}\left(\mathbf{B}_{\mathbf{T}}\right)$ & $\mathbf{E}\left(\mathbf{B}_{\mathbf{T}}\right)$ \\
\hline 1 & 160 & 160 & 160 & 160 & 160 \\
\hline 0.9 & 246 & 248 & 246 & 246 & 248 \\
\hline 0.8 & 374 & 392 & 379 & 375 & 390 \\
\hline 0.7 & 559 & 639 & 588 & 576 & 630 \\
\hline 0.6 & 819 & 1093 & 932 & 902 & 1064 \\
\hline
\end{tabular}


Table 5: Values of isothermal bulk modulus $\mathrm{B}_{\mathrm{T}}(\mathrm{GPa})$ for $\mathrm{MgO}$ at $\mathrm{T}=2000 \mathrm{~K}$

\begin{tabular}{|c|c|c|c|c|c|}
\hline V/Vo & $\mathbf{A}\left(\mathbf{B}_{\mathrm{T}}\right)$ & $\mathbf{B}\left(\mathbf{B}_{\mathrm{T}}\right)$ & $\mathbf{C}\left(\mathbf{B}_{\mathrm{T}}\right)$ & $\mathbf{D}\left(\mathbf{B}_{\mathbf{T}}\right)$ & $\mathbf{E}\left(\mathbf{B}_{\mathrm{T}}\right)$ \\
\hline 1 & 128 & 128 & 128 & 128 & 128 \\
\hline 0.9 & 205 & 206 & 204 & 204 & 206 \\
\hline 0.8 & 323 & 339 & 325 & 321 & 335 \\
\hline 0.7 & 501 & 577 & 521 & 509 & 560 \\
\hline 0.6 & 763 & 1036 & 851 & 822 & 984 \\
\hline
\end{tabular}

The values of pressure derivative of isothermal bulk modulus $\mathrm{B}_{\mathrm{T}}{ }^{\prime}(\mathrm{GPa})$ for $\mathrm{MgO}$ at different temperatures have been calculated using Usual Tait Equation of State(A), Born Mie Equation of State (B), Shankar Equation of State (C), Vinet Equation of State (D) and Birch-Murnaghan Equation of State (E) in the tables 6 given below.

Table 6: Values of pressure derivative of isothermal bulk modulus $\mathrm{B}_{\mathrm{T}}(\mathrm{GPa})$ for $\mathrm{MgO}$ at $\mathrm{T}=1000 \mathrm{~K}$.

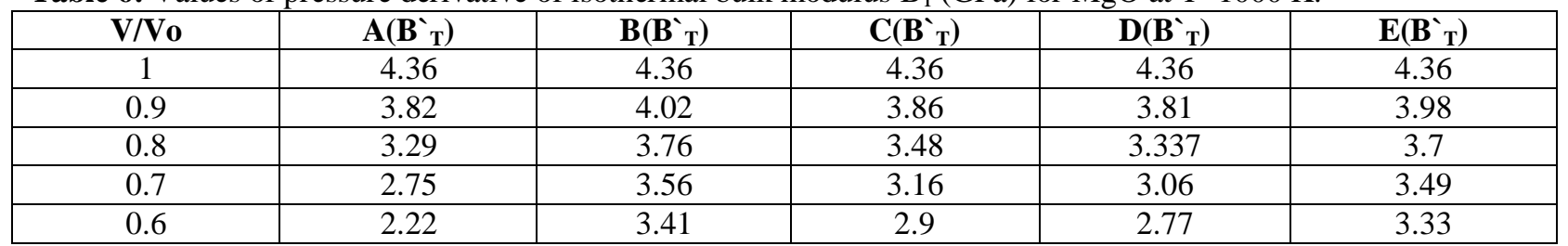

Table 7: Values of pressure derivative of isothermal bulk modulus $\mathrm{B}_{\mathrm{T}}(\mathrm{GPa})$ for $\mathrm{MgO}$ at $\mathrm{T}=2000 \mathrm{~K}$.

\begin{tabular}{|c|c|c|c|c|c|}
\hline V/Vo & $\mathbf{A}\left(\mathbf{B}_{T}^{\prime}\right)$ & $\mathbf{B}\left(\mathbf{B}_{T}{ }_{T}\right)$ & $\mathrm{C}\left(\mathrm{B}_{\mathrm{T}}{ }_{\mathrm{T}}\right)$ & $\mathbf{D}\left(\mathbf{B}_{T}{ }_{T}\right)$ & $\mathbf{E}\left(\mathbf{B}_{T}{ }_{T}\right)$ \\
\hline 1 & 4.16 & 4.16 & 4.16 & 4.16 & 4.16 \\
\hline 0.9 & 3.42 & 4.0 & 3.76 & 3.71 & 3.78 \\
\hline 0.8 & 3.09 & 3.66 & 3.22 & 3.337 & 3.7 \\
\hline 0.7 & 2.70 & 3.56 & 3.16 & 3.06 & 3.49 \\
\hline 0.6 & 2.2 & 3.31 & 2.0 & 2.48 & 3.13 \\
\hline
\end{tabular}

The values of pressure $\mathrm{P}(\mathrm{GPa})$ for $\mathrm{MgO}$ at different temperatures have been plotted using Usual Tait Equation of State (Series 1), Born Mie Equation of State (Series 2), Shankar Equation of State (Series 3), Vinet Equation of State (Series 4) and Birch-Murnaghan Equation of State (Series 5) in the graphs $2 \& 3$, given below.

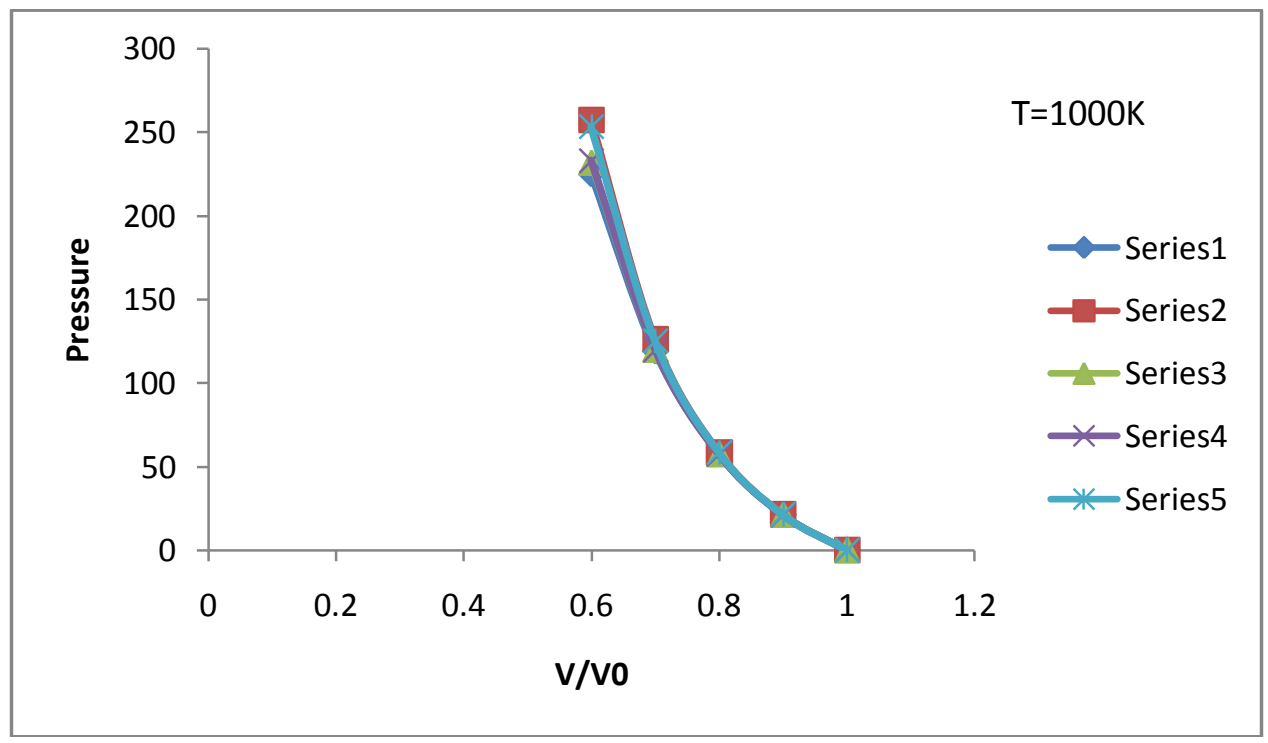

Figure 2: Pressure $\mathrm{P}(\mathrm{GPa})$ versus $\mathrm{V} / \mathrm{V} 0$ for $\mathrm{MgO}$ at $\mathrm{T}=1000 \mathrm{~K}$ 


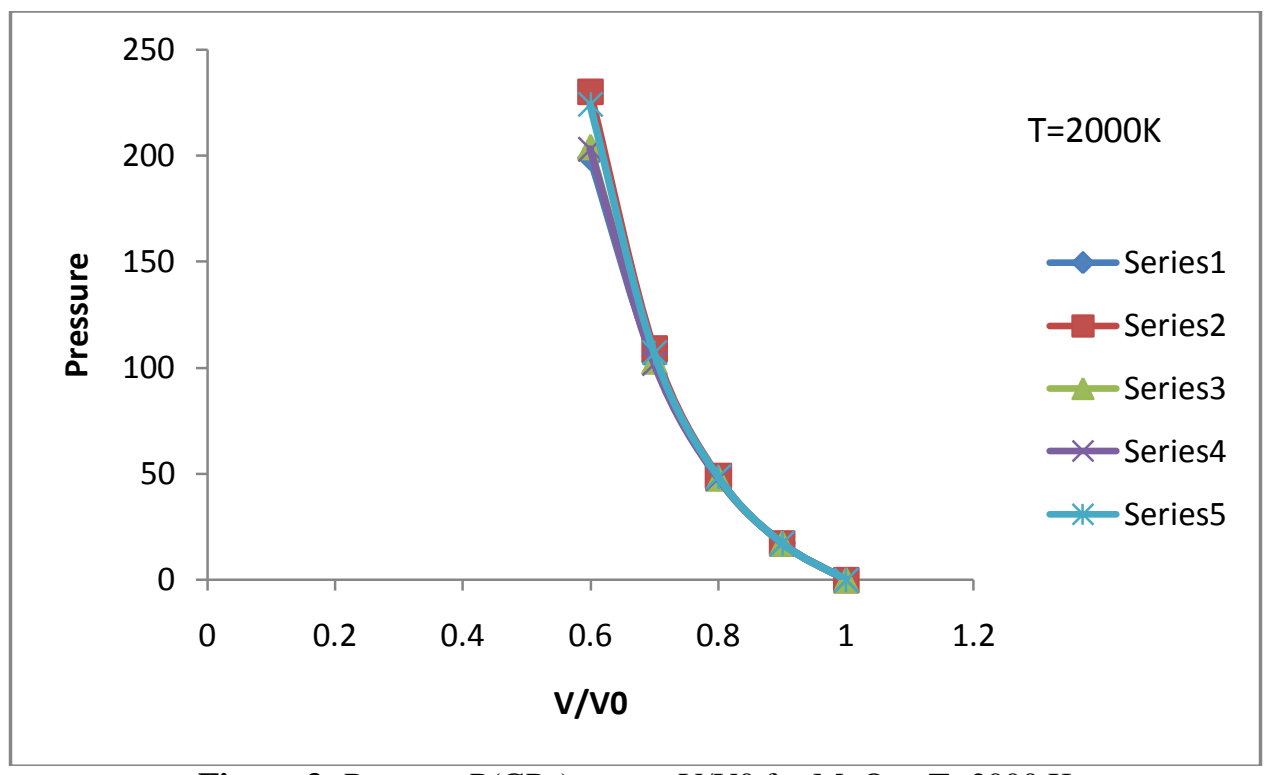

Figure 3: Pressure $\mathrm{P}(\mathrm{GPa})$ versus $\mathrm{V} / \mathrm{V} 0$ for $\mathrm{MgO}$ at $\mathrm{T}=2000 \mathrm{~K}$

The values of Isothermal bulk modulus $\mathrm{B}_{\mathrm{T}}(\mathrm{GPa})$ for $\mathrm{MgO}$ at different temperatures have been plotted using Usual Tait Equation of State (Series 1), Born Mie Equation of State (Series 2), Shankar Equation of State (Series 3), Vinet Equation of State (Series 4) and Birch-Murnaghan Equation of State (Series 5) in the graphs 4 \& 5, given below.

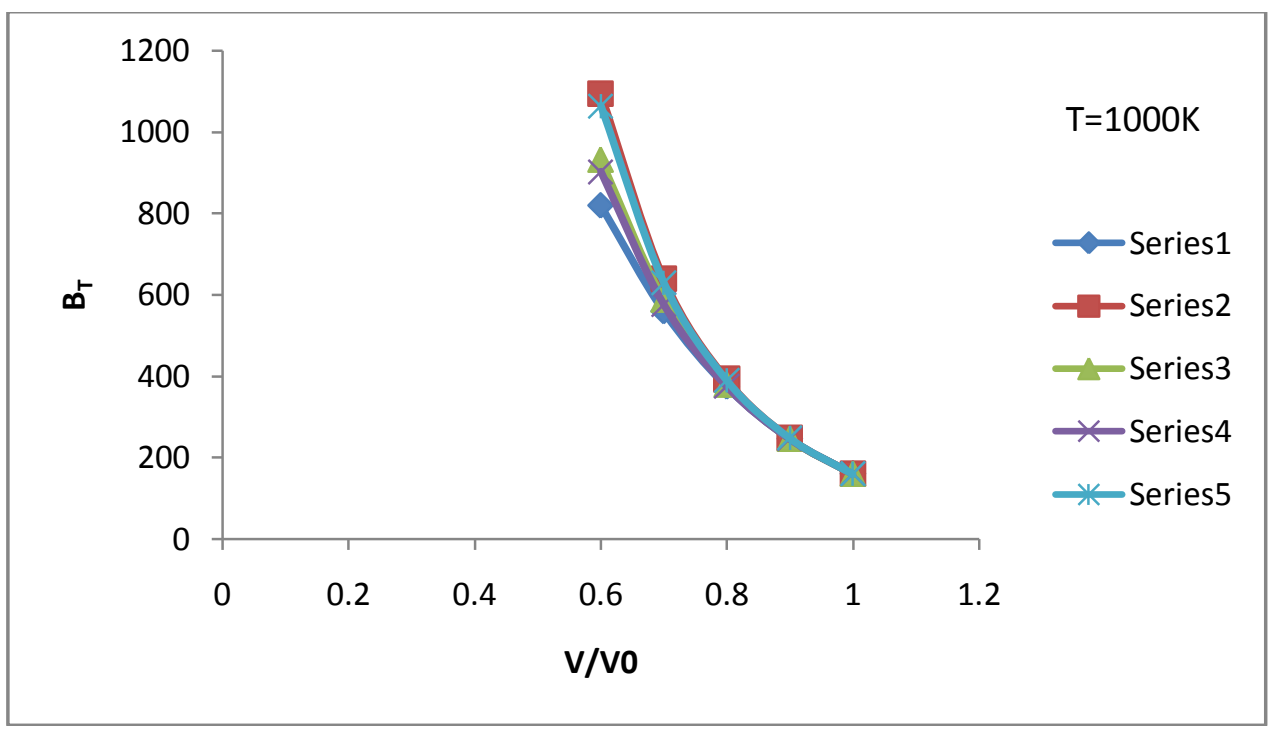

Figure 4: Isothermal bulk modulus $\mathrm{B}_{\mathrm{T}}(\mathrm{GPa})$ versus $\mathrm{V} / \mathrm{V} 0$ for $\mathrm{MgO}$ at $\mathrm{T}=1000 \mathrm{~K}$ 


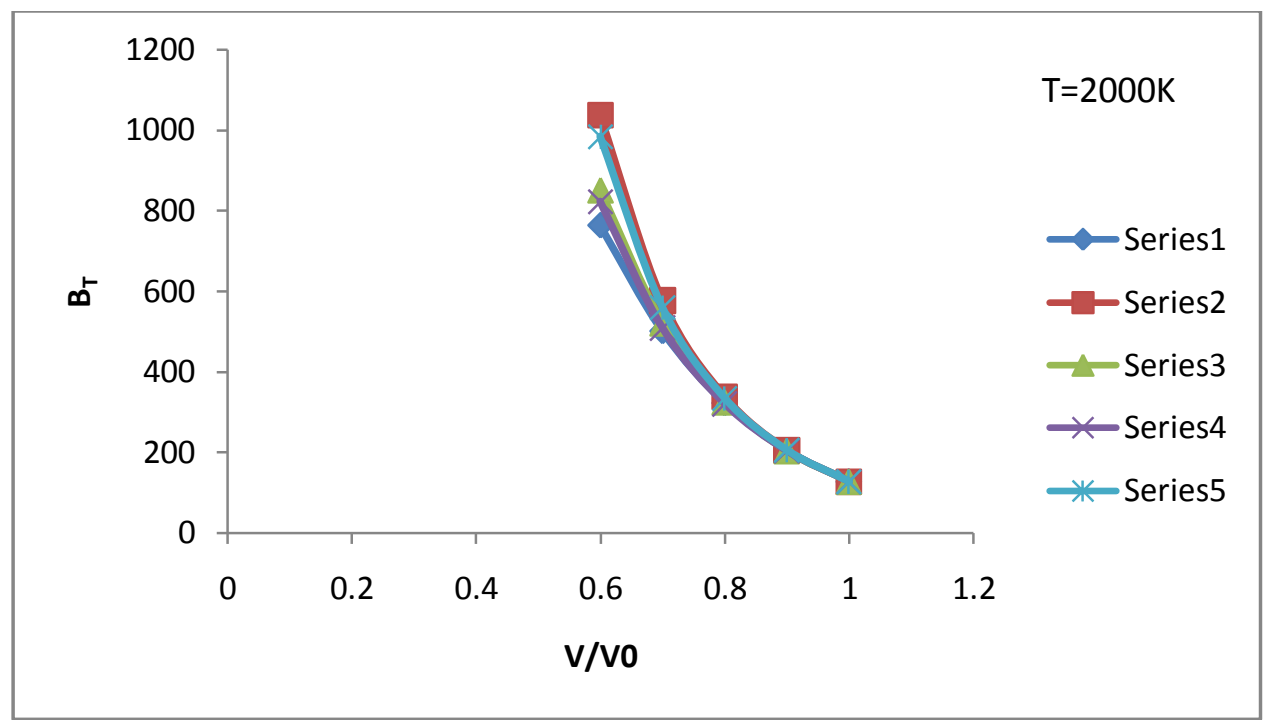

Figure 5: Isothermal bulk modulus $\mathrm{B}_{\mathrm{T}}(\mathrm{GPa})$ versus $\mathrm{V} / \mathrm{V0}$ for $\mathrm{MgO}$ at $\mathrm{T}=2000 \mathrm{~K}$.

The values of pressure derivative of isothermal bulk modulus $\mathrm{B}_{\mathrm{T}}{ }^{`}(\mathrm{GPa})$ for $\mathrm{MgO}$ at different temperatures have been plotted using Usual Tait Equation of State (Series 1), Born Mie Equation of State (Series 2), Shankar Equation of State (Series 3), Vinet Equation of State (Series 4) and Birch-Murnaghan Equation of State (Series 5) in the graphs $6 \& 7$, given below.

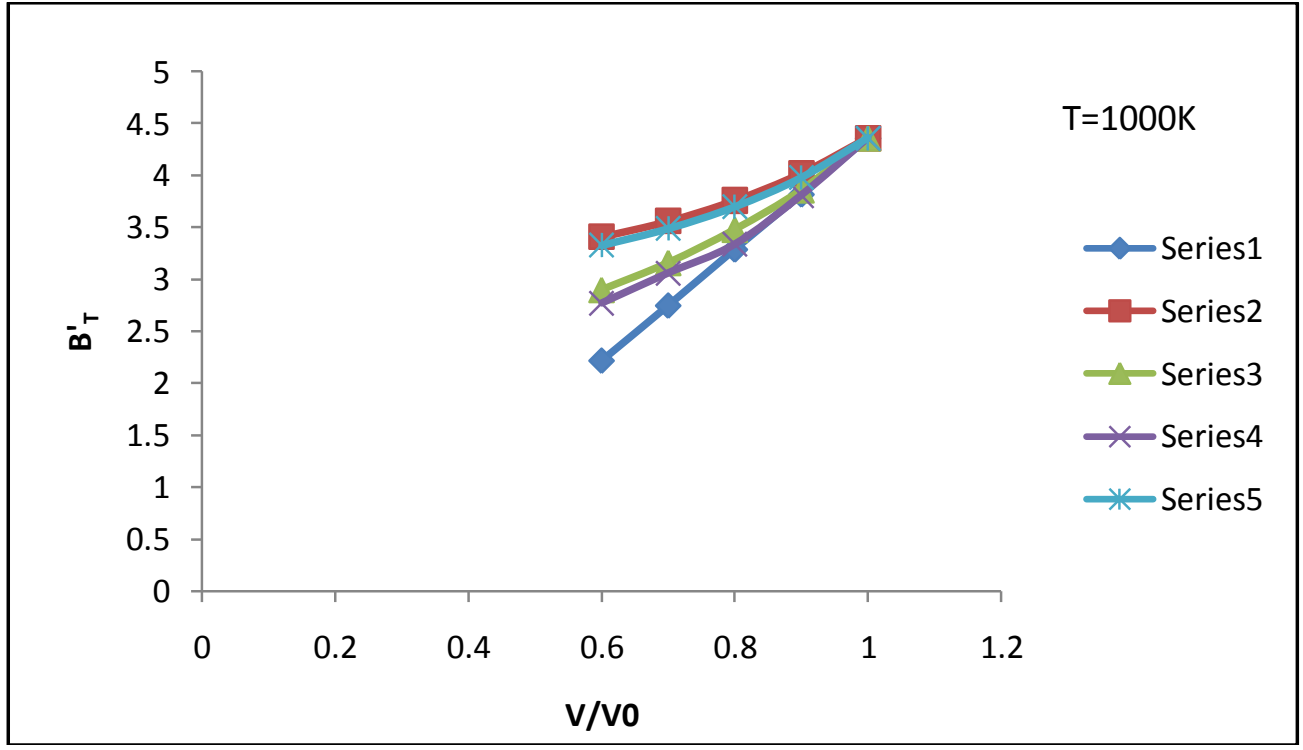

Figure 6: Pressure derivative of isothermal bulk modulus $\mathrm{BT}^{\top}(\mathrm{GPa})$ versus $\mathrm{V} / \mathrm{V0}$ for $\mathrm{MgO}$ at $\mathrm{T}=1000 \mathrm{~K}$ 


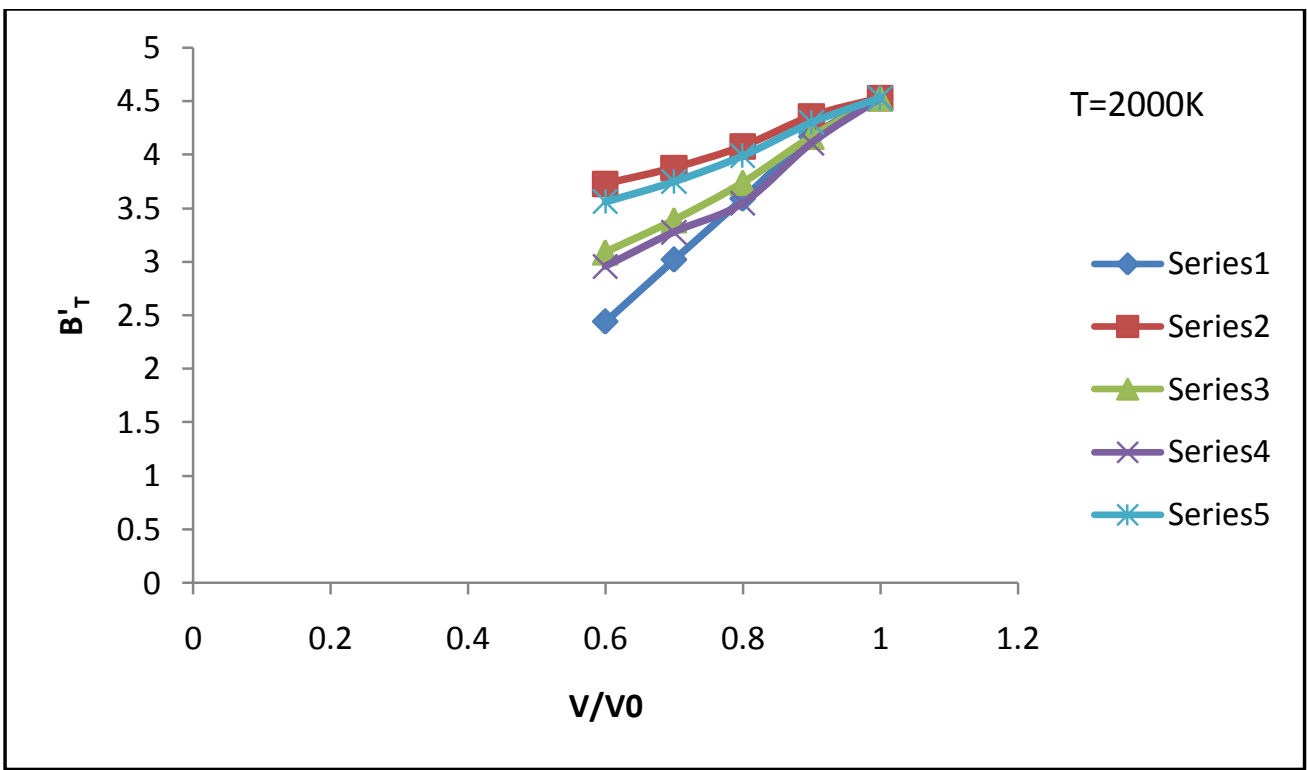

Figure 7: Pressure derivative of isothermal bulk modulus $\mathrm{B}_{\mathrm{T}}{ }_{\mathrm{T}}(\mathrm{GPa})$ versus $\mathrm{V} / \mathrm{V0}$ for $\mathrm{MgO}$ at $\mathrm{T}=2000 \mathrm{~K}$

\section{Acknowledgement:-}

The financial support from Madhya Pradesh Council of Science \& Technology Bhopal (India) under the research project is gratefully acknowledged. The authors are very much thankful to the Department of Physics Govt. Motilal Vigyan Mahavidyalaya Bhopal.

\section{References:-}

1. D.G. Isaak, R.E. Cohen, M.J. Mehl, J. Geophys. Res. 95 (1990) 7055.

2. O.L. Anderson, D.G. Isaak, J. Phys. Chem. Solids 54 (1993) 221.

3. O.L. Anderson, K. Masuda, D.G. Isaak, Phys. Earth Planet. Inter. 91 (1995) 3.

4. O.L. Anderson, Equations of State of Solids for Geophysics and Ceramic Science, Oxford University Press, New York, 1995.

5. J. Hama, K. Suito, J. Phys.: Condens. Matter 8 (1996) 67.

6. F.D. Stacey, B.J. Brennan, R.D. Irvine, Geophys. Surveys 4 (1981) 189.

7. J. Freund, R. Ingalls, J. Phys. Chem. Solids 50 (1989) 263.

8. S. Hart, P.H. Greenwood, Solid State Commun. 46 (1983) 161.

9. J.R. MacDonald, Rev. Mod. Phys. 38 (1966) 669; 41 (1969) 316.

10. A.T.J. Hayward, Brit. J. Appl. Phys. 18 (1967) 965.

11. L.M. Thomas, J. Shanker, Phys. Stat. Sol. B 189 (1995) 363.

12. M. Kumar, Physica B 212 (1995) 391; 217 (1996) 143.

13. A. Chopelas, R. Boehler, Geophys. Res. Lett. 19 (1992) 1983

14. J. Shanker, B. Singh, S.S. Kushwah, Physica B 229 (1997) 419.

15. O.L. Anderson, J. Geophys. Res. 75 (1970) 2731.

16. B.J. Brennan, F.D. Stacey, J. Geophys. Res. 84 (1979) 5535.

17. J. Shanker, S.S. Kushwah, P. Kumar, Physica B 239 (1997) 337.

18. P. Vinet, J. Ferrante, J.R. Smith, J.H. Rose, Phys. Rev. B 35 (1987) 1945.

19. P. Vinet, J.H. Rose, J. Ferrante, J.R. Smith, J. Phys.: Condens. Matter 1 (1989) 1941.

20. F. Birch, J. Geophys. Res. 91 (1986) 4949.

21. F.D. Stacey, Phys. Earth Planet. Inter. 89 (1995) 219.

22. O.L. Anderson, D.G. Isaak and H.Oda.Rev. Geophys. 30, 57(1992). 